\title{
Configurações
}

Revista de sociologia

14 | 2014

Para além da Governação. Políticas, práticas e discursos de inclusão e promoção da diversidade cultural

\section{Para além da governação. Políticas, práticas e discursos de inclusão e promoção da diversidade cultural}

\section{Beatriz Padilla e Thais França}

\section{Q OpenEdition \\ Journals}

\section{Edição electrónica}

URL: http://journals.openedition.org/configuracoes/2218

DOI: 10.4000/configuracoes.2218

ISSN: 2182-7419

\section{Editora}

Centro de Investigação em Ciências Sociais

\section{Edição impressa \\ ISBN: 1646-5075 \\ ISSN: $1646-5075$}

\section{Refêrencia eletrónica}

Beatriz Padilla e Thais França, «Para além da governação. Políticas, práticas e discursos de inclusão e promoção da diversidade cultural », Configurações [Online], 14 | 2014, posto online no dia 25 março 2015, consultado o 19 abril 2019. URL : http://journals.openedition.org/configuracoes/2218 ; DOI :

$10.4000 /$ configuracoes.2218

Este documento foi criado de forma automática no dia 19 Abril 2019.

(c) CICS 


\title{
Para além da governação. Políticas, práticas e discursos de inclusão e promoção da diversidade cultural
}

\author{
Beatriz Padilla and Thais França
}

1 Este número especial almeja promover um debate de forma crítica e reflexiva sobre a Governação da Diversidade Cultural no atual contexto latino-americano e europeu. Esta ideia surgiu no âmbito do Projeto "Multilevel governance of cultural diversity in a comparative perspective: EU-Latin America" (GOVDIV 612617) financiado pela União Europeia dentro das Ações Marie Curie - IRSES, liderado pelo Centro de Investigação em Ciências Sociais da Universidade do Minho, Portugal, em parceria com universidades europeias e latino-americanas: Universita degli Studidi Firenze (Itália), Universidad de Sevilla (Espanha), Université Paris III Sorbonne Nouvelle (França), Instituto Universitário de Lisboa (Portugal),Universidade do Estado de Santa Catarina (Brasil), Consejo Nacional de Investigaciones Científicas y Tecnológicas (Argentina), Instituto Nacional de Antropologia e História e Universidade Autónoma de Coahuila (México).

2 O GOVDIV tem como principais objetivos: a) criar uma rede transnacional interdisciplinar de investigação e formação entre a Europa e a América Latina, b) fortalecer parcerias e relações de colaborações anteriores e/ou novas entre estes contextos, c) transferir conhecimento e produzir investigação nova e inovadora através de publicações conjuntas, workshops, escolas de verão e outros tipos de intercâmbios.

3 Mesmo admitindo que a diversidade cultural pode ser entendida de forma diferente na União Europeia (UE) e na América Latina (AL), reconhecemos a diversidade cultural como um dos aspetos mais marcantes das sociedades modernas.

4 Algumas destas diferenças têm a ver com a história e os contextos sociais, políticos e económicos, próprios mas nem por isso desvinculados. Enquanto a diversidade cultural na U tem uma longa história associada às minorias étnicas (autóctones e não autóctones) e às migrações internacionais, na AL está relacionada tanto com a colonização, como com os povos originários, as migrações forçadas (escravatura) e as migrações contemporâneas. 
Contudo, em ambos os cenários, o entendimento crítico da diversidade cultural tem gerado uma crise na ideia de unidade e homogeneidade do estado-nação e dos regimes de interculturalidade e/ou multiculturalismo.

5 Desse modo, este número suscita o debate sobre a própria definição de diversidade cultural, o papel das políticas de e para a governação da dita diversidade cultural, pensando em que medida elas auxiliam uma inclusão adequada dos grupos minoritários (às vezes maioritários mas sem poder) e até que ponto promovem a sua participação na esfera pública. Compreendemos que os processos de globalização não hegemónicos tenham contribuído para o fortalecimento dos movimentos sociais que reclamam o seu reconhecimento identitário, étnico, religioso e linguístico, bem como para o aumento dos deslocamentos geográficos internacionais intensificando o encontro e o desencontro de distintas culturas.

6 Se bem que os estados-nação tenham sido atravessados por um processo de transformação que os obrigou a redefinir-se, neste número analisa-se como os estadosnação europeus e latino-americanos têm lidado com seus pressupostos de integração e reconhecimento da cidadania e como as instituições políticas têm repensado suas práticas, criando/aplicando novos regimes de governação da diversidade, quer a nível nacional, quer a nível regional ou local. Ainda que os modelos prevalecentes sejam a nível nacional, cada vez mais, outros níveis de governação têm ganhado relevância, pois, embora as políticas possam ser nacionais ou regionais, sua aplicação acontece em contextos específicos que são determinantes na forma de implementação e adaptação. Adicionalmente, alguns artigos apresentam abordagens teóricas e metodológicas sobre a Governação da Diversidade Cultural, considerando os diferentes contextos sociais, históricos, políticos e económicos.

7 Não é possível abordar a temática da diversidade cultural sem considerar o modo como esse conhecimento e a sua prática são gerados e difundidos. A geopolítica do conhecimento envolve tanto a produção de conhecimento como a sua disseminação, o que até agora tem imposto regras contrárias ao ideal das epistemologias do Sul. o Norte gera e difunde conhecimento utilizando uma multiplicidade de canais, através da disseminação de políticas migratórias, de integração, de reconhecimento da diferença e das minorias, que são vendidas como boas práticas e modelos a serem adotados pelo resto do mundo. Além disso, promove a incorporação destas ideias e respetivos/as autores/as através da obrigatoriedade da sua inclusão quer nos projetos de investigação quer nos de intervenção no circuito académico internacional hegemónico. Por um lado, estas estratégias impossibilitam, ou pelo menos dificultam, a descolonização do saber e do fazer; por outro, inibem a difusão das ideias do Sul no Norte, as quais poderiam ter um impacto positivo nas questões vinculadas à imigração e às minorias étnicas. Por outras palavras, seria possível afirmar que a Europa não valoriza ainda o que pode aprender com os contextos geopolíticos do Sul.

8 A colonialidade do poder (Quijano, 2000) sugere que o uso da raça tem sido na América Latina um padrão de poder conflitual e permanente desde a colónia até os dias de hoje. Neste número da revista Configurações os diferentes artigos são ilustrativos desta situação e também de como o modelo implantado na colónia continua igualmente vigente no próprio continente europeu, onde a raça (matizada e conjugada com a etnicidade e a nacionalidade) é um critério de exclusão da cidadania e do exercício de direitos. Atualmente isto torna-se evidente no caso dos/as cidadãos/ãs de países terceiros, os/as quais são classificados/as na categoria de maior exclusão dentro da União Europeia. A 
colonialidade do poder, como afirma Walsh, traduz-se na desumanização e no tratamento de não existência (Walsh, 2012: 30) ou, em alguns casos, em existências subalternizadas, degradadas e inferiorizadas, próprias do eurocentrismo, aplicado quer na América Latina quer na Europa. Os casos dos imigrantes do Sul na Europa e dos povos indígenas na América Latina, entre outros, ilustram essa prática.

Um dos contributos deste número é trazer à discussão trabalhos que olham para realidades e experiências diferentes, bem como críticas às respostas institucionais. Nas últimas duas décadas, muitos países da América Latina, tanto os que são parte da nova esquerda ou da viragem à esquerda (Equador, Venezuela, Bolívia, Brasil e Argentina) como os que mantêm regimes de corte mais tradicional e neoliberal (especialmente o México), têm incorporado demandas que podem ser consideradas "alternativas" e que beberam de cosmovisões autóctones dos povos originários, mesmo que influenciados por outras ideias. Após séculos de discriminação contra os povos indígenas, os negros (afrolatino-americanos) e outras minorias, vários Estados latino-americanos incorporaram, pelo menos na legislação, instrumentos legais de diferentes tipos e alcance (Constituição, leis, organismos governamentais a diferentes níveis, etc.) que pretendem ouvir as minorias e os grupos excluídos por questões linguísticas, religiosas, raciais e étnicas. No entanto, nem todas elas têm sido bem-sucedidas: algumas são significantes vazios ou uma formalidade sem recursos atribuídos.

10 A importância dos trabalhos reunidos neste número radica em apresentar a filosofi a de interculturalidade como uma proposta latino-americana diferenciada das propostas do multiculturalismo do Norte. Embora o multiculturalismo (como epistemologia e modelo do Norte) tenha sido difundido e adotado através da disseminação de conhecimentos e da exportação de modelos teóricos e legais (legislação, boas práticas, programas específicos do Norte para o Sul), os modelos e ideais de interculturalidade latino-americanos devem ser entendidos como autónomos, e não como uma subcategoria dos modelos do Norte, salvo quando incorporam elementos de ambos os modelos (especialmente nos países mais influenciados pelo pensamento do Norte, i.e., Argentina, Brasil, entre outros).

11 Segundo Walsh (2012) o multiculturalismo promove a produção e gestão da diferença dentro da ordem nacional com a expectativa de fazê-la funcional, especialmente no neoliberalismo. Por seu lado, a interculturalidade (pensada desde os povos originários e/ ou afros) aponta para transformações radicais que transcendem a tolerância ou a mera incorporação de elementos diferentes da matriz estabelecida, pretendendo reconceptualizar as estruturas sociais numa lógica de relações equitativas que incorporem práticas e modos diversos de pensar e viver.

Neste sentido o projeto de interculturalidade latino-americano é um processo em construção que ultrapassa a inter-relação e comunicação, indicando

procesos de construir y hacer incidir pensamientos, voces, saberes, prácticas, y poderes sociales "otros"; una forma "otra" de pensar y actuar con relación a y en contra de la modernidad/colonialidad. No nos referimos aquí a un pensamiento, voz, saber, práctica y poder mas, sino unos pensamientos, voces, saberes, prácticas y poderes de y desde la diferencia que desvían de las normas dominantes radicalmente desafiando a ellas, abriendo la posibilidad para la descolonización y la edificación de sociedades más equitativas y justas. Por eso, la interculturalidad y la decolonialidad deben ser entendidos como procesos enlazados en una lucha continua. Una lucha dirigida a enfrentar y desestabilizar las construcciones e imaginarios de nación y designifica América "Latina" concebidos por las elites locales, la academia y el occidente, y a hacer construcciones e imaginarios distintos, 
así a la vez poniendo en cuestión la noción que las soluciones a los problemas y crisis de la modernidad tienen que venir de la modernidad misma. (Walsh, 2012: 35-36) artigo "Del discurso a lo hechos: el Estado mexicano y los pueblos indígenas de México" no qual analisa o conteúdo do Programa Especial para os Povos Indígenas 2014-2018 do governo mexicano, que segue o modelo de mediação dialética da comunicação social, tentando explicar qual a relação atual destes povos com o Estado. A análise identifica uma falta de compromisso genuíno por parte do Estado mexicano com os povos originários, mesmo sendo este um dos temas principais na agenda oficial. políticas públicas y contrucción de hegemonía en la Argentina kirchnerista: el caso INADI", Cecilia Melella, do Consejo Nacional de Investigaciones Científi cas y Tecnológicas (CONICET), Argentina, avalia a implementação de políticas públicas por parte do Instituto Nacional contra la Discriminación, la Xenofobia y el Racismo. Inovadoras quanto aos seus objetivos, estas políticas acabam contudo, no seu labor, por criar significantes vazios dos quais a interculturalidade é um exemplo. No seu seio, as demandas a serem esgrimidas são muito diversas e pretendem mais aprofundar a democracia plural kirchnerista que atender a demandas específicas.

18 Gabriel Pérez Salazar, da Universidade Autónoma de Coahuila, México, no artigo intitulado "La diversidad linguística en los espacios virtuales en México: Un análisis crítico desde la Sociedad de la Información", mostra como o México desenha políticas 
para integrar as minorias linguísticas (leia-se também étnicas) na Sociedade da Informação como elemento de desenvolvimento. Contudo, não tem tido sucesso nem conseguido uma melhoria significativa neste campo. Pelo contrário, as estratégias implicam um tecnodeterminismo que não consegue ultrapassar as limitações estruturais, começando pela não afetação de recursos orçamentais que consigam fazer a diferença.

19 A perspetiva europeia chega da mão de Sonia Hernández-Plaza, da Universidade do Minho, no artigo “¿Diversidad cultural o desigualdad social? Una aproximación crítica a la competencia cultural en la salud a partir de las necesidades sentidas por mujeres en contextos de diversidad, injusticia social y austeridad", que nos traz um caso do âmbito da saúde. A autora faz uma leitura crítica e alternativa da denominada competência cultural, mostrando como esta perde relevância em momentos de crise económica e de austeridade.

Gabriela de la Peña Astorga, da Universidade Autónoma de Coahuila, no seu artigo "El problema de la deserción escolar y las possibilidades de la investigación-acción participativa", partilha uma experiência concreta de investigação ação participativa no âmbito da realização de investigação em comunicação, visando uma intervenção concreta com mulheres jovens no contexto educativo. Mesmo tendo um carácter metodológico preponderante, o leitor aprende como funciona este tipo de investigação e como é aplicada a populações vulneráveis e em contexto de exclusão social.

Pelo seu lado, Maria Soledad Balsas, do Consejo Nacional de Investigaciones Científicas y Tecnológicas (CONICET), Argentina, em "La imagen de la mujer inmigrante en los libros de texto argentinos", faz uma análise crítica da narrativa hegemónica sobre as migrações para a Argentina, a qual por um lado invisibiliza a mulher e por outro transmite uma ideia estereotipada do papel dessas mulheres. A análise dos livros sobre ciências sociais destinados ao nível secundário mostra que estas obras restringem as mulheres imigrantes ao espaço doméstico, apresentando-as como importantes, sobretudo, para a demografia do país. Mais além, no mesmo artigo, é possível ainda distinguir diferenças substanciais entre as mulheres imigrantes provenientes do continente europeu e as latino-americanas.

22 Em uma outra perspetiva, Francesco Gervasi, da Universidade Autónoma de Coahuila, no artigo "No tendrás dioses ajenos delante de mí: notas sobre la diferenciación y la intolerancia religiosas en México", reconstrói o campo religioso mexicano descrevendo as práticas de intolerância e racismo que sofrem as minorias religiosas neste país. De acordo com a sua análise, embora o México se proclame defensor da diversidade religiosa, está longe de o conseguir.

23 A variedade de temas e as distintas realidades abordadas neste número ilustram como as reflexões da interculturalidade, mais do que pertinentes, são necessárias no contexto europeu e latino-americano. Convidamos, portanto, os/ as leitores/as a desfrutar dos contributos deste número, dando atenção especial à sua perspetiva descolonial. 


\section{BIBLIOGRAPHY}

PADILLA, Beatriz; AZEVEDO, Joana \& OLMOS-ALCARAZ, Antonia (2014), "Superdiversity and conviviality: exploring frameworks for doing ethnography in Southern European intercultural cities", Ethnic and Racial Studies. http://dx.doi.org/10.1080/01419870.2015.980294.

QUIJANO, Aníbal (2000), “Colonialidad del poder y clasifi cación social”. Journal of World Systems Research 6 (2), 342-386.

WALSH, Catherine (2006), "Interculturalidad y (de)colonialidad: diferencia y nación de otro modo", em Magalhães Neto, Hamilton (Coord.), Desarrollo y interculturalidad, imaginario y diferencia: la nación en el mundo Andino. Rio de Janeiro: Academica de la Latinidad, 27-43.

\section{AUTHORS}

\section{BEATRIZ PADILLA}

CICS - Universidade do Minho

\section{THAIS FRANÇA}

CICS - Universidade do Minho 